УДК 811.521

DOI: $10.24044 / \mathrm{sph} .2017 .4 .27$

\title{
СТИЛИСТИКО-СИНТАКСИЧЕСКИЕ ОСОБЕННОСТИ ЯЗЫКА МАНГА
}

\author{
3. Б. Степанова \\ С. М. Неустроева
}

\author{
Стариий преподаватель, \\ ORCID 0000-0002-0643-9327, \\ e-mail: zbstepanova@mail.ru, \\ cтудент, ORCID 0000-0002-4161-4469, \\ e-mail: sargy1009@gmail.com, \\ Северо-Восточный федеральный университет \\ имени М. К. Аммосова, \\ 2. Якутск, Республика Саха (Якутия), Россия
}

\section{STYLISTIC AND SYNTACTIC FEATURES OF THE MANGA LANGUAGE}

\author{
Z. B. Stepanova \\ S. M. Neustroeva
}

\author{
Senior lecturer, ORCID 0000-0002-0643-9327, \\ e-mail: zbstepanova@mail.ru, \\ student, ORCID 0000-0002-4161-4469, \\ e-mail: sargy1009@gmail.com, \\ M. K. Ammosov North-Eastern Federal University, \\ Yakutsk, The Republic of Sakha (Yakutia), Russia
}

\begin{abstract}
In this article, the authors consider syntactic constructions of sentences, which strengthen the expressiveness of the text in manga. The authors explain and give relevant examples of these syntactic constructions: ellipsis, preterition, rhetorical question, reduplication. Also, the authors consider the peculiarities of the transfer of intonation to manga through inversion, punctuation and graphics. The authors pay attention to means of strengthening expressiveness, such as variant spelling of words and other ways of organizing written text.

Keywords: manga; syntax; stylistic figure; syntactic construction; Japanese language; expressivity; abbreviation; graphics.
\end{abstract}

Каждый функциональный стиль имеет свои индивидуальные особенности в плане синтаксических построений предложения, которые внедряются в художественные произведения, тем самым усиливая стилистический эффект. Литературный язык манга избыточен разнообразными синтаксическими построениями, среди которых обнаруживаются перераспределение границ предложения, эллиптические предложения, смещенные конструкции, в которых конец предложения представлен в другом синтаксическом строе, чем в начале, а также обособленные друг от друга элементы одного высказывания.

Традиционная стилистика определяет синтаксические построения, которые усиливают экспрессивность высказывания, изобразительно-выразительными сред- ствами языка, стилистическими фигурами. В «Словаре лингвистических терминов» О. С. Ахманова дает следующий определение этому термину: стилистическая фигура или фигура речи - «оборот речи, особое сочетание слов, синтаксическое построение, используемые для усиления выразительности высказывания» [1]. Наиболее частыми для японского комикса являются эллипсис, умолчание, риторический вопрос, повторы.

Эллипсис представляет собой пропуск элемента, который подразумевается в контексте предложения: O-jozudesune! - Iie, hanashita koto wa Amari nakatta mono desuga - Вы прекрасно владеете японским языком! - Нет, совсем не было возможности говорить по-японски. В этом диалоге опущено слово «nihongo» - японский 
язык. Тем не менее оно легко восстанавливается по контексту.

Умолчание - структурная и логическая незавершенность предложения, благодаря чему читатель сам догадывается о недосказанном (из контекста либо из ситуации): Ран: «Watashiwaikanai». - Соноко: «Kyo:shyukuwake» (Ран: «Я не пойду». Соноко: «Потому что ты смущена»).

Риторический вопрос является хорошим способом привлечения внимания читателя к тому или иному явлению, ситуации в тексте. Этот вопрос-утверждение имеет положительный либо отрицательный характер, не требующий ответа. «Masakaome: oyogene:njane: noka?» «Неужели ты не умеешь плавать?»; «Kеіjitteoyogenakutemonarerundesuka?» - «Значит можно стать следователем и не умея плавать?» Или «munashiiyume» - «пустые надежды».

Повтор - фигура речи, состоящая в повторении звуков, слов и выражений в известной последовательности [1]. Данная стилистическая фигура выражает субъективно-оценочное отношение говорящего к предмету речи: «Gyokosa! Shizukaninarimashita. Gyokosa!» - «Повезло. Стало тихо. Повезло!»

В манга также характерно передачи интонации при помощи знаков препинания, средствами графики. В японском языке очень распространен прием инверсии - помещения в необычную позицию какой-либо части речи с целью повышения выразительности речи; поэтому благодаря инверсии усиливается внутренняя интонация письменного высказывания. «Anatawaikimashitaka. Asokoe?» - «Ты ездил туда?»; «Oyomininarimashita, kohohon.» - «Они прочли эту книгу»; «Wasuremashita.

Ju:su:nengatachimashitakara». - «Забыли. Это потому что прошло более десяти лет».

Картинки в комиксе располагаются вертикальными рядами в некоторой логической последовательности. Синтаксическая связь между ними строится по принципу монтажа и смены планов, их сово- купность передает некое драматическое действие.

В манга наиболее часто используется диалогичная форма речевого общения, при которой герои напрямую связаны между собой и могут свободно делать дополнительные разъяснения, исправлять неточности или изъяснять что-либо непонятное своим собеседникам. Однако, в комиксе присутствуют монологи, выражающие мысли героя, а также имеют место и слова автора. Кроме того, в нем не соблюдают строго точность и ясность речи; в ней часто можно обнаружить неполные предложения, участники речевого контакта обходятся недомолвками, которые угадываются довольно легко, и, наоборот, полнота речи выступает как излишнее утяжеление, неуместный педантизм.

С точки зрения синтаксиса манга при помощи знаков препинания можно добиться пауз, заминок и резкого интонационного перелома в речи героя. Тембр, интенсивность, паралингвистическое сопровождение речи иллюстрируется в большинстве случаев наглядно (кричал, размахивая руками; посмотрел, сощурив глаза).

В плане синтаксической организации в манга часто используются экспрессивносинтаксические конструкции, упрочивающие индивидуальность речи, улучшающие ее диалогичность и спонтанность, удаляющие безликость и безадресность речи и т.д. В японском языке экспрессивность в основном выражается с помощью пунктуации, вариантных написаний слов (при одном и том же произношении) и другими способами организации письменного текста [3, с. 25]. Известно, что в японском языке слово может допускать несколько, а то и много вариантов написания, и, соответственно, любой текст - бесчисленное количество инвариантов исполнения. Однако эти вариации совсем не равнозначны, каждый из них имеет свое значение и особую ценность.

В японских комиксах (манга) знаки препинания играют исключительную роль и отличаются большим разнообразием, 
чем в других жанрах письменной речи. В рассмотренных нами японских комиксах часто встречаются необычные вариации тире (сверхдлинные, волнистые и пр.), изощренно-изобретательные комбинации вопросительного и восклицательного знаков: !!!, !!!!, !!?, !! !? и т. П., экспрессивность которых нередко усилена наклоном: !!!!!, а также различные необщепринятые аналоги этих знаков, символизирующие ту или иную аффективную окраску речи: рисунок сердечка, обозначающий что-то вроде 'с нежностью', например: “ 私は幸せけ»'Я счастлива...', или рисунок ноты, передающий певучесть, и т. п.

Также в комиксах и неформальной рукописи часто встречаются необычные способы передачи долготы гласных: например, слог ко:, может быть написан не только стандартными способами: «こう », «こお» и, но также и экзотическими, вроде «こー», «コオオ», «コーー». В подобных случаях орфографическая нестандартность усиливает экспрессию речи, часто придавая ей шутливый характер.

Используется и вариативность написания слов для описания характера персонажа. Характер может трактоваться иногда по-разному, если то, как герой себя называет написано хираганой, катаканой и иероглификой. Скажем, «боку» (я; употребляется обычно в неформальной речи представителями мужского пола), написанное иероглифом может скрыто символизировать ум, если хираганой - высказано «мальчиком из хорошей семьи», катаканой - вездесущим озорникомодноклассником. Таким образом, буква несет за собой значительную смысловую роль. Неоднократно встречается превращение хираганы в катакану, делая акцент на преобразованное слово. Данный способ подчеркивания отчасти аналогично сплошным заглавным буквам в латинице или кириллице. В комиксе «Детектив Конан» катакана служит для выделения ре- плики героя: Хэйдзи вдруг взорвался... вскочил... и заорал: ...поищи какогонибудь идиота, который сумеет расшевелить тебя!». В оригинале здесь применяются иероглифика и катакана, что резко выделяется на фоне всего остального текста с его обычной графикой: иероглифика и хирагана. Читатель сразу понимает, что герой вне себя, мы почти слышим его искаженный голос.

Катакана на тех местах, где нормально ожидалось бы хирагана, в высшей степени характерна для передачи речи персонажей в японских комиксах: это один из приемов усиления экспрессивности. Например: «すげ 一ヨナ» или «スゲーヨナ» «сугэ:ёна» 'Вот это да!', 'Во даёт!' (обычное написание - « すげえ»; «сугэ:» - стилистически сниженный вариант слова «сугои» 'ужасный, поразительный’); «ワタシ、ケッコン», кеккон 'Я вышла / выхожу' ( более обычным было бы написано: «わたし、結婚).

Буквенные аббревиатуры, целиком построенные на использовании латиницы, широко употребляются в Японии, можно привести примеры таких буквенных аббревиатур, как ОK (произносится о:кэ:) 'окэй', ВF (произносится би:эфу) 'бойфренд', OL (о:эру) 'конторская служащая' (от officelady), NG (энудзи:) 'неудачная запись на радио, телевидении' (от nogood), SGI (эсудзи:ай) 'Сока-ГаккайИнтернационал' (наименование сети зарубежных филиалов японской религиозной организации Сока Гаккай).

Таким образом, в ходе исследования нами были рассмотрены следующие синтаксические конструкции характерные в манга: эллипсис, умолчание, риторический вопрос, повторы. Данные выше примеры этих стилистических фигур показывают усиление образно-выразительной функции речи, выполняя прагматическую функцию метафоризации слов в тексте манга. Также рассматривались на основе примеров спо- 
собы, передающие настроение и интонацию высказывания - через пунктуацию, графические средства, как и факторы, усиливающие экспрессию текста.

\section{Библиографический список}

1. Ахманова О. С. Словарь лингвистических терминов. - М., 1969. - 327 с.

2. Жукова И. В. Стилистика японского языка. M., 2002. - $111 \mathrm{c}$.

3. Маевский Е. В. Графическая стилистика японского языка. - М., 2000. - 176 с.

4. Gosho Aoyama. Meitantei Konan.-Vol. 31. Tokio, 2001. - 197 c.

\section{Bibliograficheskij spisok}

1. Ahmanova O. S. Slovar' lingvisticheskih terminov. - M., 1969. - 327 s.

2. Zhukova I. V. Stilistika japonskogo jazyka. - M., 2002. - $111 \mathrm{~s}$.

3. Maevskij E. V. Graficheskaja stilistika japonskogo jazyka. - M., 2000. - 176 s.

4. Gosho Aoyama. Meitantei Konan.--Vol. 31. Tokio, 2001. - 197 s.

(C) Степанова 3. Б., Неустроева С. М., 2017. 